\title{
Microscopic dynamic observation of adhesion hysteresis friction and exploration of the influence of different pressures on friction transmission
}

\author{
Cun-ao FENG ${ }^{1,2}$, De-kun ZHANG ${ }^{3, *}$ Kai CHEN $^{3}$ \\ ${ }^{1}$ School of Mechatronic Engineering, China University of Mining and Technology, Xuzhou 221116, China \\ ${ }^{2}$ Department of Mechanical Engineering, University of British Columbia, Vancouver V6T1Z4, Canada \\ ${ }^{3}$ School of Materials Science and Engineering, China University of Mining and Technology, Xuzhou 221116, China \\ Received: 23 April 2019 / Revised: 05 September 2019 / Accepted: 12 February 2020 \\ (C) The author(s) 2020.
}

\begin{abstract}
The mechanism of adhesive friction between viscoelastic materials is a key question. In this study, the friction process of the adhesive interface between a friction lining and a wire rope is dynamically observed in real time to analyze the adhesion hysteresis friction intuitively and quantitatively. The adhesion is determined by the state of motion, while the relative displacement of the wire rope and lining is used to find the magnitude of the adhesive friction. The hysteresis friction is reflected by the internal deformation of the lining. The magnitude of the hysteresis friction is determined by the displacement difference $(\Delta x)$ in the sliding direction of two marked points at different distances from the contact surface. The results show that the adhesion friction is proportional to the loss modulus and the hysteresis friction is proportional to the ratio of the loss modulus to the square of the storage modulus $\left(E^{\prime \prime} /\left(E^{\prime 2}\right)\right)$. The frictional vibration first decreases and then increases with the increase in pressure. The K25 lining has the highest adhesion hysteresis friction and minimal frictional vibration. The result provides a simple and intuitive method for research into the friction transmission and vibration of viscoelastic materials.
\end{abstract}

Keywords: adhesion hysteresis friction; viscoelasticity; frictional vibration; dynamic monitoring

\section{Introduction}

China is paying increasing attention to the long-term safety and mechanization of coal mining. Mining is also being modernized, and the application of multi-rope friction hoist is becoming widespread $[1,2]$. The multi-rope friction hoist mainly relies on the friction between the friction lining on the friction wheel and the wire rope. Friction is the key factor in ensuring safety. The friction lining is a viscoelastic material, meaning there is adhesion hysteresis friction between the friction lining and the wire rope. During the friction process, the lining will continuously adhere, deform, and break, generating vibration [3, 4]. Moreover, the wire rope is a flexible body, and elastoplastic deformation occurs after being stressed. The transmission of vibration through the flexible wire rope will also continue to increase. Therefore, once a slight vibration generated at the friction pair, the transmission in a kilometer-long flexible wire rope results in a large vibration shake to the lifting container. The vibration is a great hazard to the entire lifting system [5]. Therefore, it is very important to explore the mechanism of adhesion hysteresis friction and its influencing factors in the process of friction transmission.

Adhesive friction is the force at which adhesion occurs at the interface to hinder sliding. Hysteresis friction is a repetitive periodic deformation of a

* Corresponding author: De-kun ZHANG, E-mail: dkzhang@cumt.edu.cn 
viscoelastic material due to compression and sliding, resulting in a lag in the horizontal component (hysteresis friction) that hinders sliding. In the research of the adhesion hysteresis friction mechanism of viscoelastic materials, Lü and Li [6] found the friction coefficient (COF) and wear of nitrile rubber decreased with increasing load, showing hysteresis friction at lower loads and adhesion friction at higher loads. At lower sliding speeds, the change in load produced a simple molecular mechanical fracture. Wang et al. [7] found the friction factor between a tire and a road surface included two parts of adhesion and hysteresis. The adhesion COF was the average COF, which could be used to describe the elastic and friction characteristics of the tire when sliding completely or slipping. Tong et al. [8] used the multi-scale method of molecular dynamics and finite element coupling to find that the larger the radius of the indenter was, the larger the surface friction. The friction increased as the depth of depression of the indenter increased, and adhesion hysteresis occurred at low speeds. Jrad et al. [9-11] combined the rheological and friction properties of viscoelastic materials and pointed out the friction characteristics of the materials were closely related to energy loss. A rheological model considering the relationship between torque and angular displacement (rotation) was established. Tambe et al. [12, 13] found the scale of the COF depended on the surface roughness and scan size of the sample. For larger scan sizes, the sliding interface encountered larger micro-protrusions and the friction was large. Lafaye et al. [14] found the apparent friction and true local friction peak were related to the loss factor. The peak of the ploughing friction was related to the contact asymmetry. Moreover, the root of the contact asymmetry was the viscoelasticity or plasticity, and the adhesion hysteresis was the real cause of the local friction.

The above researches are based on the results of the occurrence and the theoretical knowledge to reversely deduce the process of adhesion hysteresis friction. No occurrence and evolution of the adhesion hysteresis friction were observed. With the rapid development of the dynamic capture system of cameras, it has become a useful tool for detecting the dynamic evolution process of inquiry [15]. Chen et al. [16, 17] used a high-speed micro-camera to observe the contact friction interface of the GM-3 friction lining in real time, and the actual contact area of the contact interface was calculated. Chromik et al. [18] used optical microscopy and Raman spectroscopy to observe the sliding behavior of the sapphire and coating interface, the friction and wear behavior, and the structural chemical changes of the subsurface. Krick et al. [19] designed an in-situ observation test machine to study the actual contact area of nitrile rubber and transparent glass under different working conditions. During the loading and unloading process, the contact area had a significant hysteresis. Czchos [20] summarized the interfacial friction phenomenon from the macroscopic scale to the microscale and the nanoscale. The wear mechanism was studied by scanning electron microscopy to further observe the real-time generation process of abrasive particles. Korres et al. [21] used an immersion holographic microscope to observe the smooth sliding copper surface and determined the evolution process of the wear trajectory. The production of flaky wear particles was mainly studied. De Beer et al. [22] found that the dissipated energy of polymer brushes affect the frictional response to relative motion.

Regarding the research on the friction drive and vibration of a hoist, Gao et al. [23] found the COF was reduced owing to the humid working environment of the hoist. The tension of the main rope was alternating to cause self-excited vibration. Wang et al. [24] found the dynamic contact state included viscous, slip, and mixed states during the lifting process. An increase in the lifting weight led to an increase in the possibility of overall slippage. The stress concentration increased and the wear between the contacts accelerated. Kaczmarczyk and Ostachowicz [25] found the vibrations include external resonance, parametric resonance, and self-resonance resonance. When the winding speed changed, the resonant position shifted. Yao and Xiao [26] performed a dynamic analysis of the vertical hoisting wire rope. It was found that at the second-order excitation frequency, when the hoisting load was in the range of $0-5,000 \mathrm{~kg}$, a large lateral amplitude difference generated. This caused the adjacent two cascades to collide and accelerated the breakage of the wire rope. 
The previous studies have focused only on the overall friction drive of the system and have not paid attention to the fact that adhesion friction is the driving force for lifting. This means the effect of adhesive friction on the overall friction drive and vibration has been ignored. Therefore, the adhesive hysteresis friction is tracked and quantified by real-time dynamic observation in this study to explore the adhesion hysteresis friction mechanism. The influence of different pressures on adhesion hysteresis friction and frictional vibration is explored. The motion state is determined by the displacement of the interface, and the adhesion is determined by the state of motion. The relative displacement of a wire rope and a lining is used to reflect the magnitude of the adhesive deformation and adhesive friction force. The hysteresis friction force is reflected by the size of the internal deformation of the lining. The frictional vibration is measured by monitoring the deformation displacement in the vibration direction.

\section{Experimental}

\subsection{Experimental materials}

Three types of friction linings commonly used in Chinese coal mining are selected for testing: K25, G30, and GM-3. The friction lining is made of a composite material, and the high-strength heat-resistant resin and rubber are compounded and modified as a matrix material. The fillers are montmorillonite, $\mathrm{CaCO}_{3}$, and other space fillers. Meanwhile, the functional additives are rubber additives, including cross-linkers, plasticizers, accelerators, and antioxidant agents. The basic performance parameters are included in Refs. [16, 17].

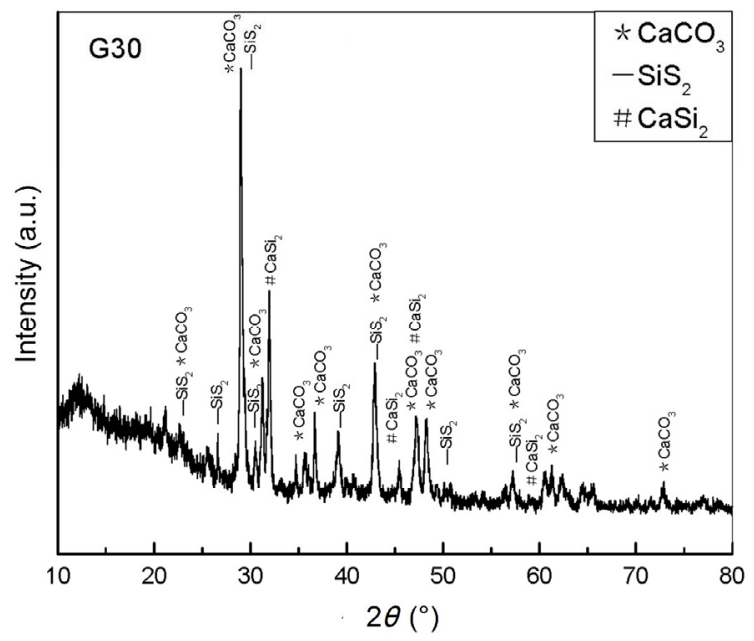

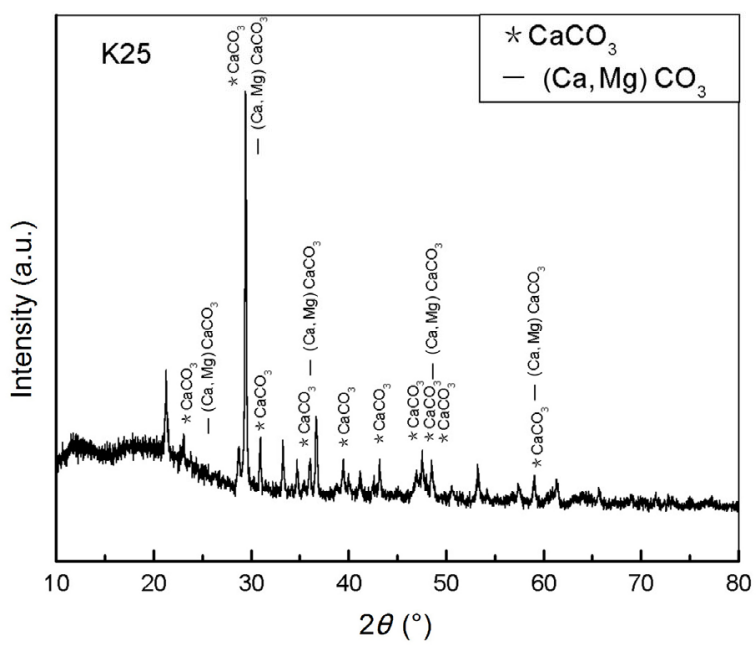

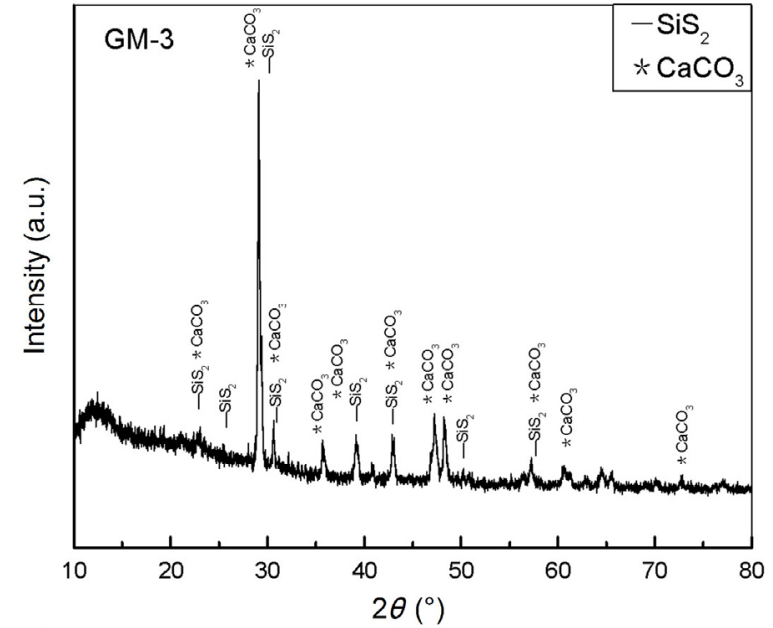

Fig. 1 Patterns of the XRD analysis related to friction lining. 
The results of the X-ray diffraction (XRD) test are shown in Fig. 1. The shore hardness $(D)$ of the K25, G30, and GM-3 linings was 63.5, 76.5, and 70.5, respectively. The friction linings samples were ground and polished before the test, and their roughness $(R a)$ was $0.4 \mu \mathrm{m}$. The material of the wire rope was carbon steel.

\subsection{Experimental methods}

The self-developed test platform simulates the arcsurface contact and friction condition of the friction lining and wire rope during the actual lifting process. The test platform and a schematic of the experiment are presented in Fig. 2. The loading force is generated by tightening the wire rope with an electric cylinder. This causes the wire rope to press against the friction lining to the predetermined pressure $\left(T_{1}, T_{2}\right)$. The motor drives the reciprocating micro-slip motion of the friction lining to simulate the friction of the lifting process. The lens of a high-speed micro-camera (VW9000) is aligned with the contact interface to monitor the viscoelastic contact and friction between the friction lining and wire rope. The observation area is shown in the red dotted frame in Fig. 2. The COF is calculated by monitoring the dynamic change of the tension at both ends of the wire rope $(\mu=(1 / \alpha) \times$ $\ln \left(T_{1} / T_{2}\right)$, where $T_{1}$ and $T_{2}$ denote the tension on both sides of the wire rope and $\alpha$ is the arc length of the lining ( $\alpha=21^{\circ}$ in this experiment)) [4]. The frame rate of the high-speed camera is $200 \mathrm{fps}$, the resolution of each pixel is $640 \times 480$, and the shutter speed is $1 / 2,000 \mathrm{~s}$.

Points were respectively marked on the wire rope and friction lining. The tracking system was used to record the movement trajectory of the two-dimensional space during the friction process, as shown in Fig. 3. For accuracy, our dynamic observation experiment

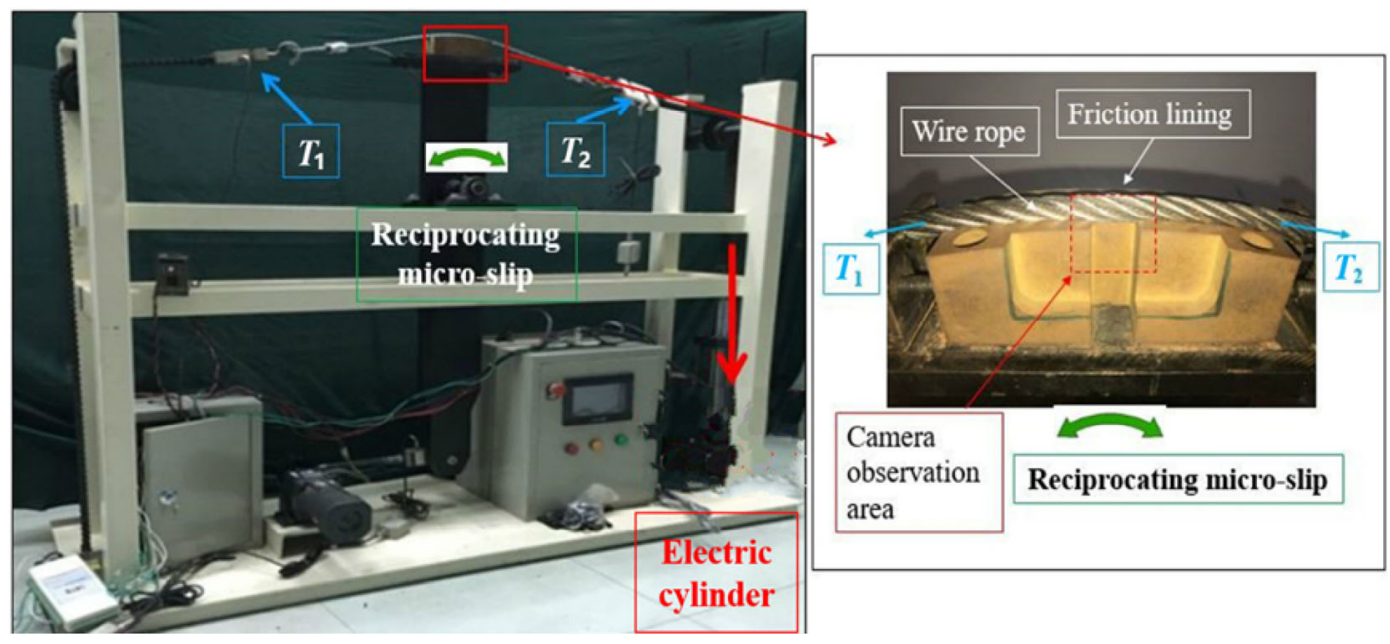

Fig. 2 Schematic of the experiment.
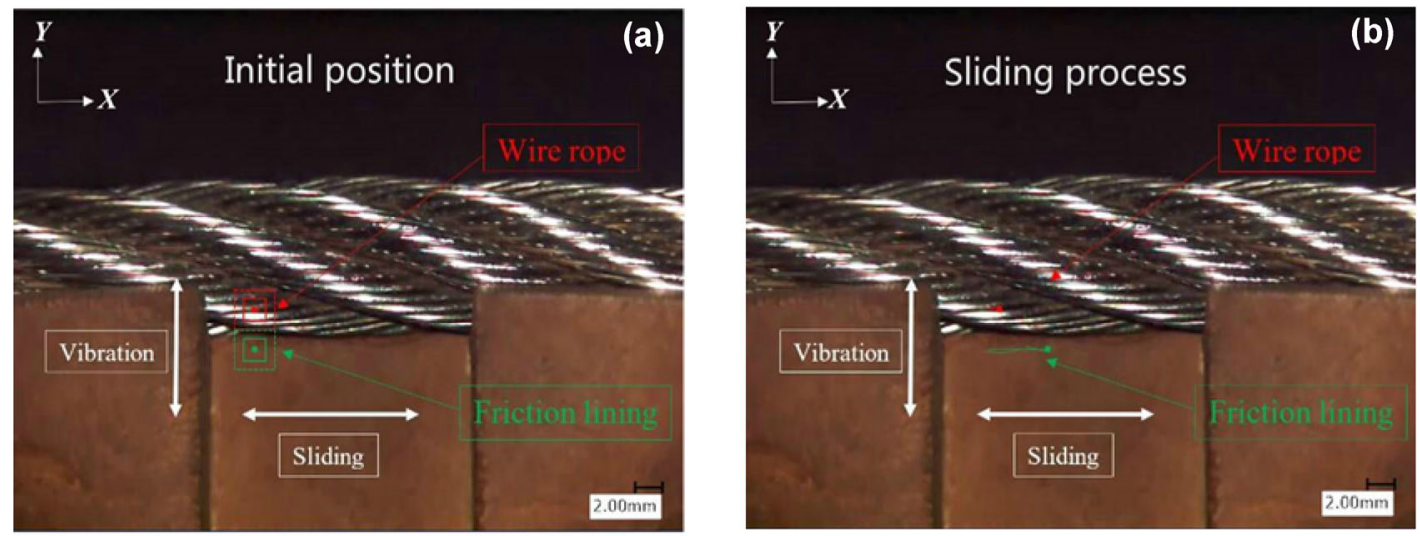

Fig. 3 Tracking the displacement of the marked points: (a) Initial position and (b) sliding process. 
took one data point every $0.004 \mathrm{~s}$. The displacements of the friction lining and wire rope in the sliding direction (the $X$-direction) and in the vibration direction (the $Y$-direction) during the whole friction process were obtained. The changes in the adhesion friction (sliding direction) and vibration during the friction were analyzed. The measurement accuracy was $0.0001 \mathrm{~mm}$.

To further explore the hysteresis friction phenomenon in the friction process, a point was marked at $1 \mathrm{~mm}$ from the contact surface on the friction lining, and another point was marked at $3 \mathrm{~mm}$ directly, as shown in Fig. 4. The displacements of the two points in the sliding direction were recorded. Because of the adhesion on the contact surface and the driving force on the friction lining, tensile deformation occurred inside the friction lining, and hysteresis friction occurred. Thus, the sliding displacement of point 2 was ahead of the displacement of point 1 , as shown in Fig. 4(b). Figure 4(c) shows the displacement in the sliding direction of the marked points 1 and 2 . It can also be observed that the displacement of point 2 is ahead of that of point 1 , and the displacement has a jump, because elastic recovery occurs after the tensile deformation. This type of response is relatively small relative to the overall sliding distance, which is not obvious in Fig. 4(c). Therefore, to better analyze the displacement of the two marked points in the sliding directions, the displacement of the two marked points is subtracted to obtain the displacement difference $(\Delta x) . \Delta x$ is the change in tensile deformation in the sliding direction. It can reflect the change in hysteresis friction.

In the experiment, $6 \times 19+$ IWS point contact wire rope with a diameter of $12 \mathrm{~mm}$ was used. Before the test, the surface of the friction lining and the wire rope should be pretreated following the Chinese standard JB/T 10347-2002 and the coal industry standards MT/ T248-1991. The experiment requires the surface of the friction lining and wire rope should be free of water, grease, and other impurities, and the wire rope should not be embroidered. The experimental parameters are listed in Table 1. The projection pressure of the friction hoist during use was 1-3 MPa. The creep speed of the friction lining during the lifting process was generally less than $8 \mathrm{~mm} / \mathrm{s}$. Therefore, the selected pressure range was 1-3 MPa and the sliding speed was $4 \mathrm{~mm} / \mathrm{s}$. The pressure in the experiment is the projection pressure.
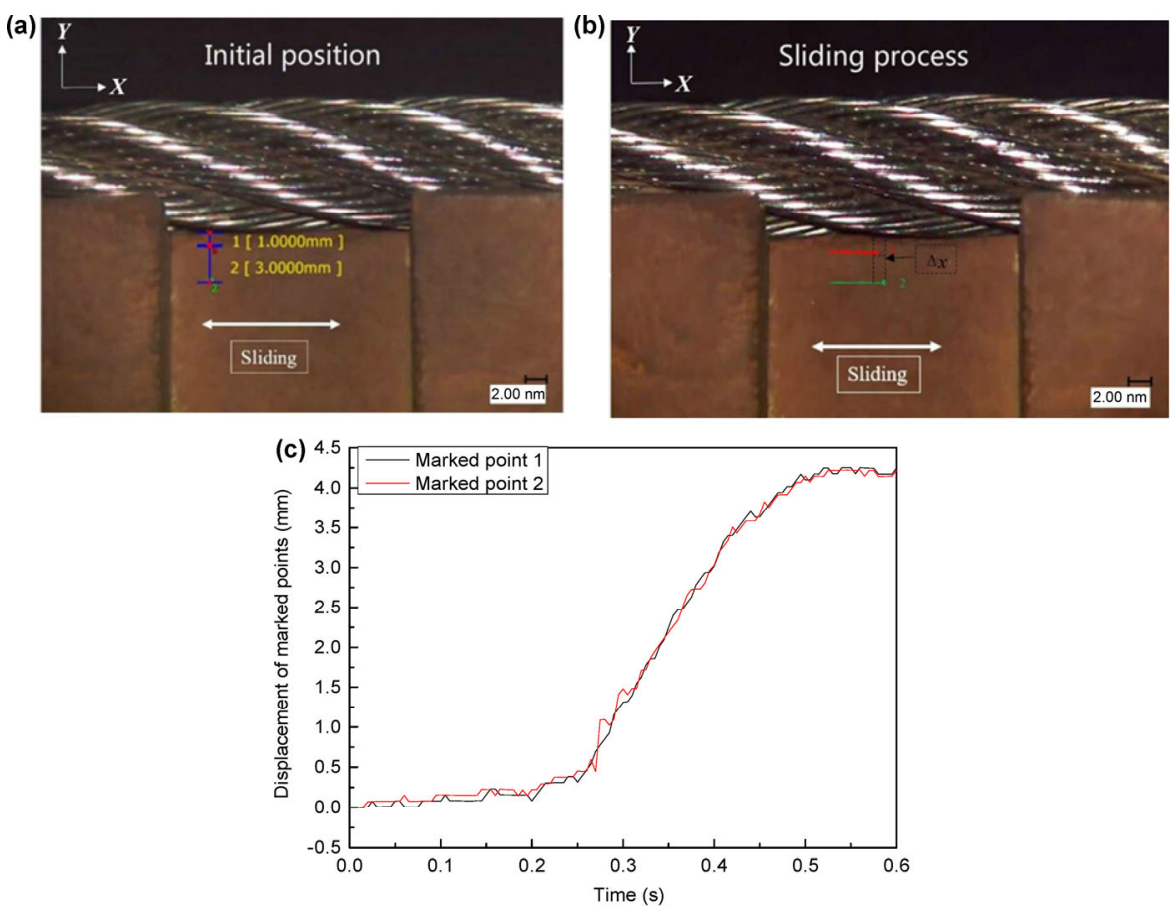

Fig. 4 Tracking the displacement of marked points 1 and 2 in the friction process: (a) Initial position, (b) sliding process, and (c) displacement of marked points 1 and 2 in the sliding direction. 
Table 1 Experimental parameters.

\begin{tabular}{cc}
\hline Parameter & Value \\
\hline Pressure $(\mathrm{MPa})$ & $1,1.5,2,2.5,3$ \\
Sliding speed $(\mathrm{mm} / \mathrm{s})$ & 4 \\
Sliding distance $(\mathrm{mm})$ & 6 \\
Time $(\mathrm{min})$ & 10 \\
Temperature $\left({ }^{\circ} \mathrm{C}\right)$ & 25 \\
Lubrication condition & Dry friction \\
\hline
\end{tabular}

\section{Results}

\subsection{Dynamic observation of adhesive friction under different pressure conditions}

Figure 5 shows the displacement of the K25 lining and wire rope in the sliding direction under different pressure conditions. In Fig. 5(a), at the beginning of the experiment, the K25 lining adhered to the wire rope, and the change rule was the same. After $0.2 \mathrm{~s}$, the displacement of the lining increased rapidly, and the displacement of the wire rope fluctuated slightly. The increase rate of both is different, which indicates that a relative slip occurred between the lining and the wire rope. At $0.5 \mathrm{~s}$, the displacement of the lining reached the maximum value. Then, it changed in the reverse direction. It still adhered first, then slipped, and changed periodically. The variation law under different pressure conditions is consistent. Therefore, the friction process can be divided into two phases: the adhesion and sliding stages [5]. Comparing Figs. 5(a)-5(e), it can be observed as the pressure increases, the time of the adhesive stage becomes longer, but the adhesion is unstable. The fluctuations become larger, the sliding time becomes shorter, and the displacement of the lining in the sliding direction decreases. As the pressure increases, the displacement of the adhesive stage is tilted, causing the boundary line to become blurred, especially at $3 \mathrm{MPa}$ in Fig. 5(e).

In Fig. 5, the displacements of the friction lining and wire rope in the adhesive and sliding stages have simultaneously small fluctuations of the same amplitude. This indicates that there is an adhesive motion (the contact interface adhesion causes the friction lining to move together with the wire rope). The fluctuation indicates a tendency to move during the adhesive stage and a re-adhesion during the sliding stage. The type of fluctuation is a form of adhesiondestruction. The time of occurrence is also short, which can be defined as stick-slip fluctuation. As the pressure increases, the stick-slip fluctuation of the K25 lining becomes larger, especially at $3 \mathrm{MPa}$ in Fig. 5(e).
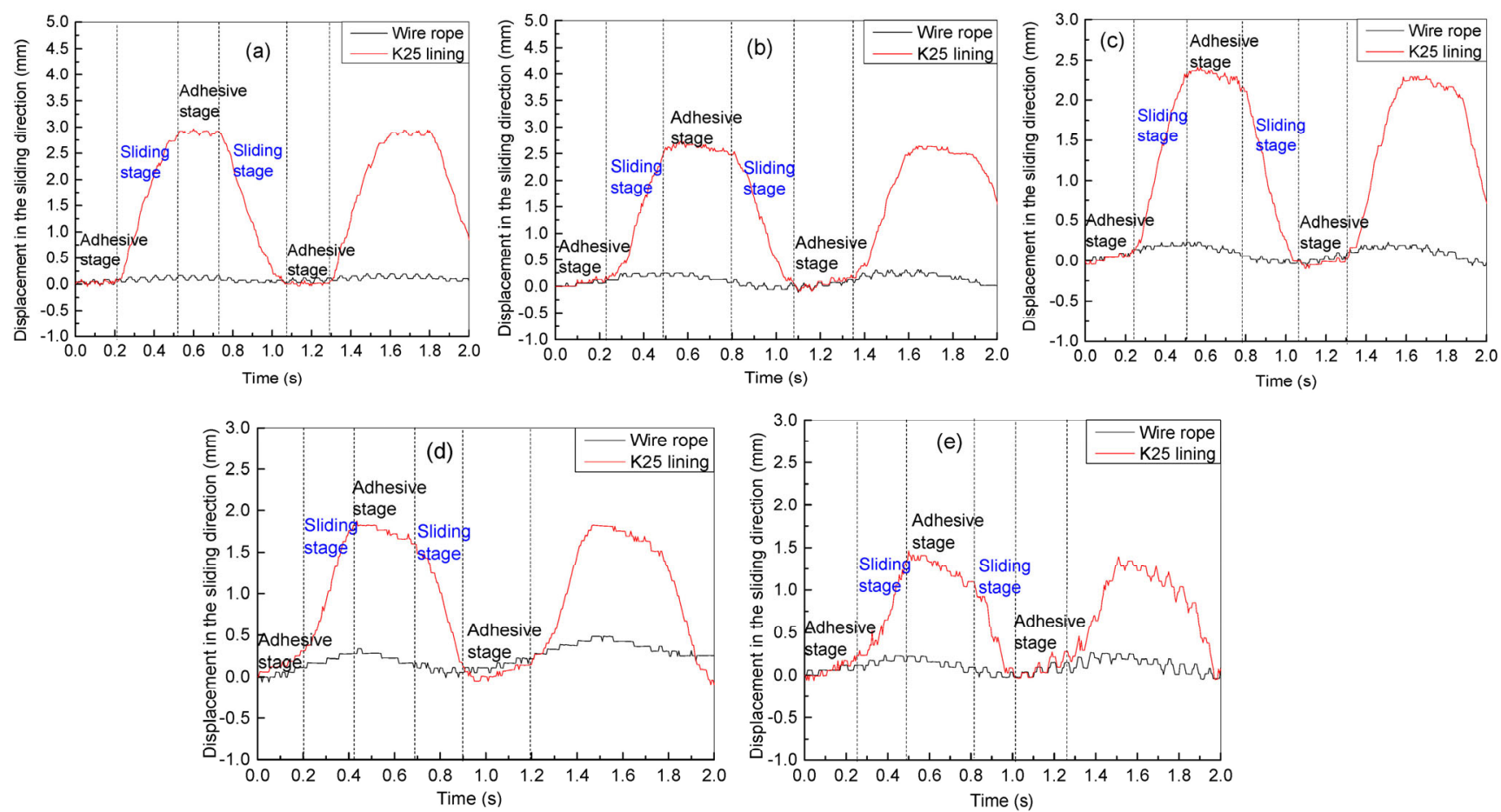

Fig. 5 Displacement of the K25 lining and wire rope in the sliding direction at: (a) 1, (b) 1.5, (c) 2, (d) 2.5, and (e) $3 \mathrm{MPa}$. 
Therefore, the boundary between the adhesion and sliding stages becomes blurred at $3 \mathrm{MPa}$.

Figure 6 shows the displacement of the G30 lining and the wire rope in the sliding direction under different pressure conditions. In Fig. 6, the displaycement change of the G30 lining in the sliding direction is similar to that of the K25 lining. It also adhered first and then slipped, and it can be divided into the adhesion and sliding stages. As the pressure increases, the displacement of the G30 lining in the sliding direction also decreases, and the time of the adhesive stage becomes longer. At low pressures (1 and $1.5 \mathrm{MPa})$, the stick-slip fluctuation is small. At high pressures, the stick-slip fluctuation is more obvious, especially at $3 \mathrm{MPa}$ in Fig. 6(e).

Figure 7 shows the displacement of the GM-3 lining and wire rope in the sliding direction under different pressure conditions. The adhesive and sliding stages are divided as shown in Fig. 7. The displacement of the GM-3 lining in the sliding direction also decreases as the pressure increases, and the time of the adhesive stage becomes longer. At pressures of 1.5 and $2 \mathrm{MPa}$, the stick-slip fluctuation is small. When the pressure is large, the stick-slip fluctuation is more obvious, especially at $3 \mathrm{MPa}$ in Fig. 7(e).The stick-slip fluctuation of the GM-3 lining first reduces and then gradually increases with pressure increasing.

For a clearer comparison of the relationship between the adhesion sliding distance and the pressure, the displacements of the friction lining and wire rope in the sliding direction are subtracted. In Fig. 8, the relative sliding distances of the friction lining decrease as the pressure increases. The relative sliding distance of the K25 lining is the smallest. As the pressure increases, the relative sliding distance decreases, and the amount of decrease is smaller. The relative sliding distance of the G30 lining is large. As the pressure increases, it decreases rapidly, and then decreases slowly. This shows that the relative sliding distance has a greater influence on the lower pressure. The relative sliding distance of the GM-3 lining is also large. As the pressure increases, it decreases slowly, decreases rapidly at pressures of 2 and $2.5 \mathrm{MPa}$, and then slowly decreases. This indicates the critical point is at a pressure of $2.5 \mathrm{MPa}$.

To quantify the maximum relative sliding distance and adhesive time of the friction lining under different pressures more effectively (the adhesion friction is
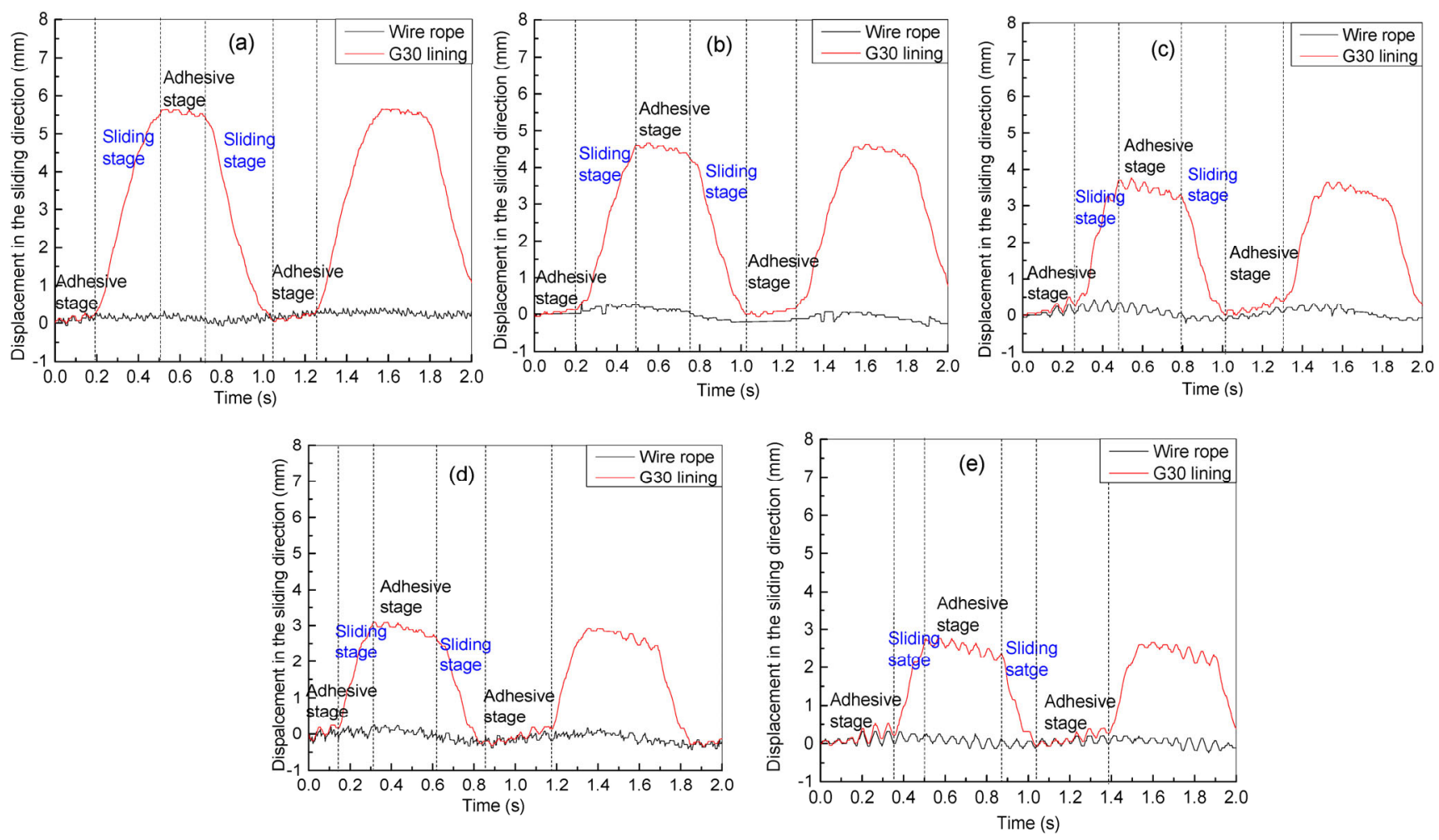

Fig. 6 Displacement of the G30 lining and wire rope in the sliding direction at: (a) 1, (b) 1.5, (c) 2, (d) 2.5, and (e) 3 MPa. 

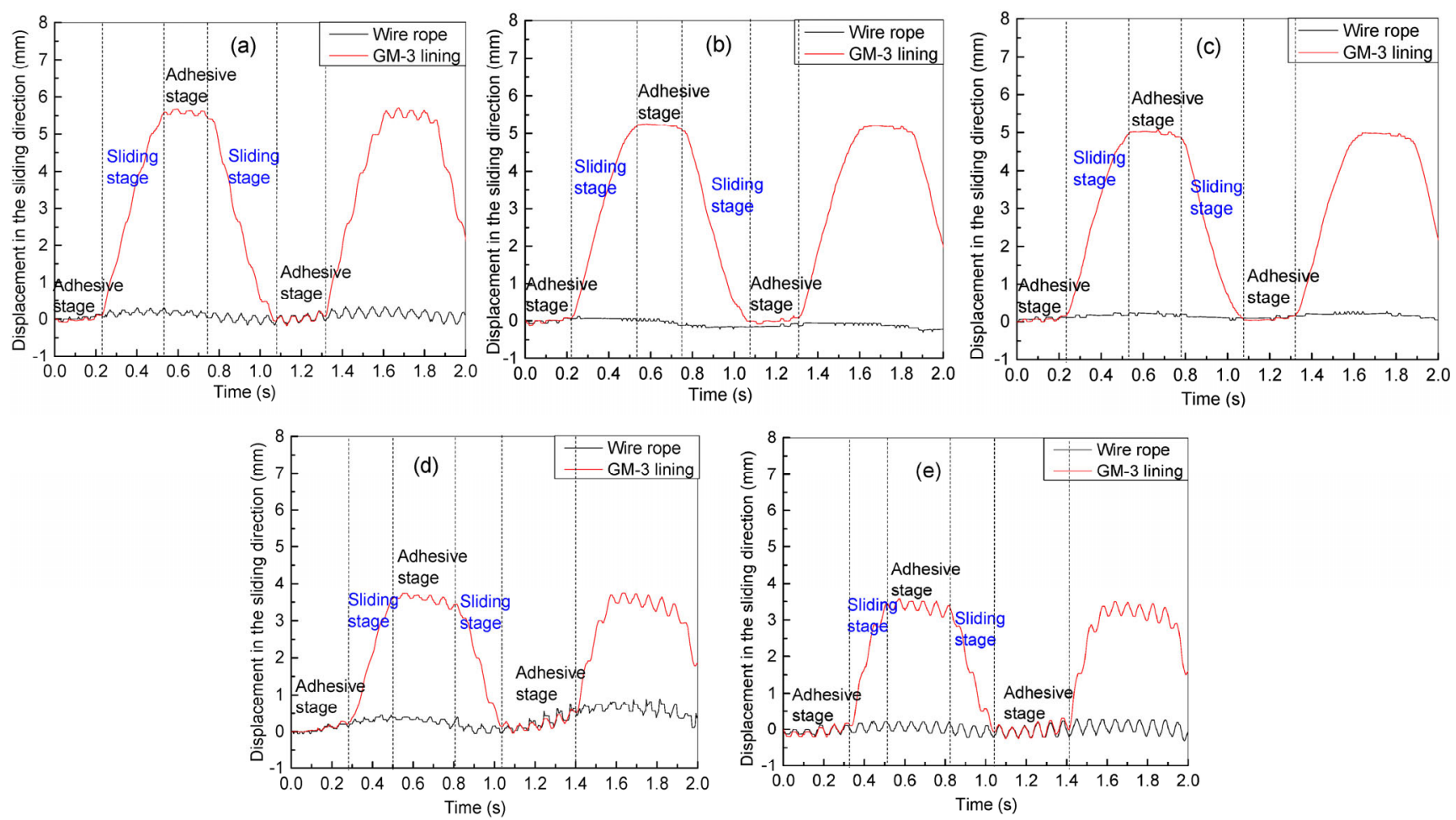

Fig. 7 Displacement of the G30 lining and wire rope in the sliding direction at: (a) 1, (b) 1.5, (c) 2, (d) 2.5, and (e) 3 MPa.
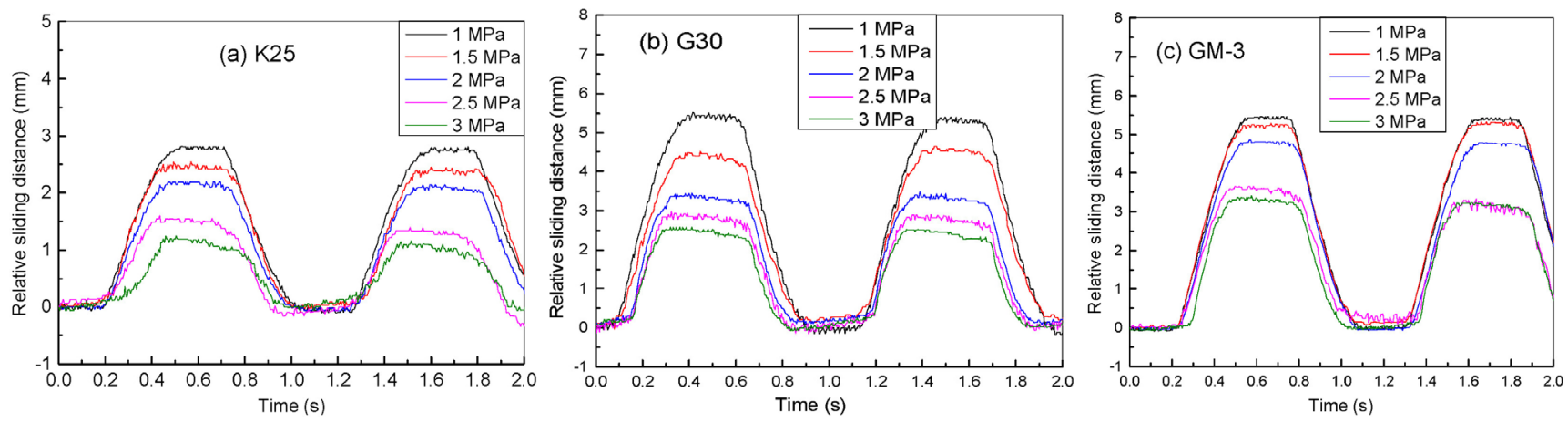

Fig. 8 Relative sliding distance of the friction lining in the sliding direction: (a) K25 lining, (b) G30 lining, and (c) GM-3 lining.

related to the maximum relative sliding distance and the adhesive time), and in accordance with the above results of the adhesion and sliding stages, the average values of the adhesive stage time and the maximum relative sliding distance were obtained. The results are shown in Fig. 9. The pressure increases, the maximum relative sliding distance decreases, the adhesive time increases rapidly first, and then tends to be stable. The maximum relative sliding distance of the $\mathrm{K} 25$ lining is the smallest under different pressure conditions. The adhesive time is longer than that of the GM-3 lining at the pressures of 1.5 and $2 \mathrm{MPa}$. At the pressures of 2.5 and $3 \mathrm{MPa}$, although the maximum relative sliding distance is much smaller than that of the G30 and GM-3 linings, the adhesive time is almost the same. Therefore, the adhesion friction of the K25 lining is the largest. The relative sliding distance of the G30 lining is medium. The adhesive time is the longest. Therefore, the adhesion friction is small. The maximum relative sliding distance of the GM-3 lining is the largest and the adhesive time is also the shortest. Thus, the adhesion friction is small.

\subsection{Dynamic observation of hysteresis friction under different pressure conditions}

Figure 10 shows the $\Delta x$ in the sliding direction of two 

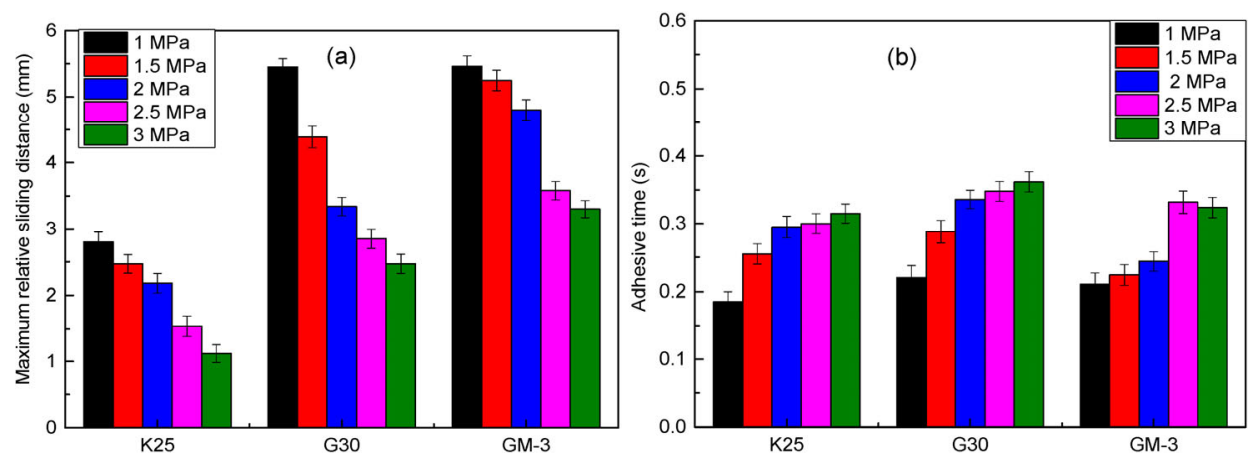

Fig. 9 Maximum relative sliding distance and adhesive time of the friction lining under different pressures: (a) Maximum relative sliding distance and (b) adhesive time.
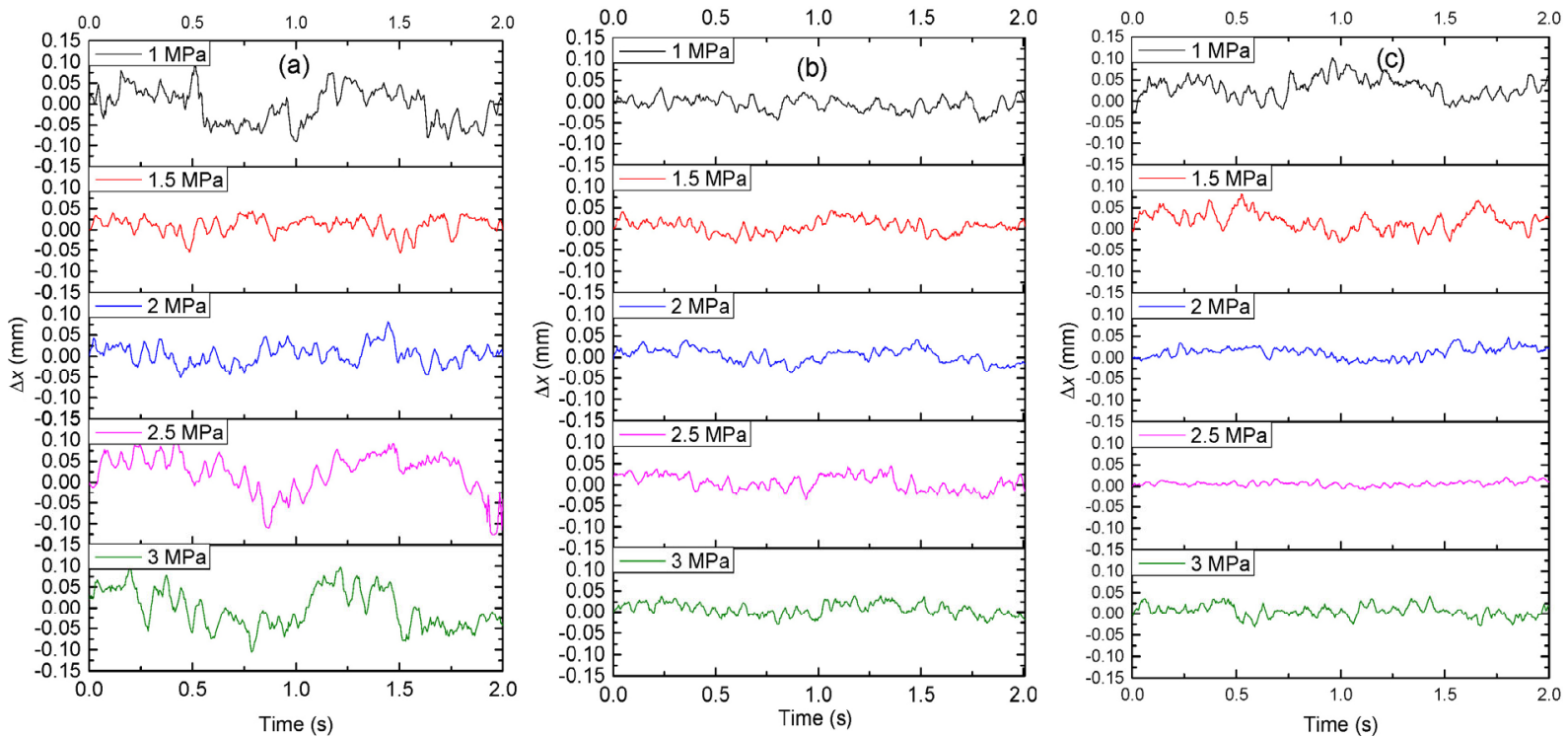

Fig. $10 \Delta x$ of the friction lining in the sliding direction: (a) K25 lining, (b) G30 lining, and (c) GM-3 lining.

marked points at different distances from the contact surface during the friction process. The tensile deformation (hysteresis friction) inside the friction lining is reflected. In Fig. 10(a), when the friction started, the tensile deformation inside the friction lining started to increase, and then fluctuated continuously. This shows the adhesion-recovery continuously happened. Then, the $\Delta x$ changed in reverse. As the pressure increases, the $\Delta x$ of the K25 lining first decreases and then increases, and the fluctuation at $1.5 \mathrm{MPa}$ is small. The $\Delta x$ of the G30 lining under different pressures are small. This reveals that the internal stretch of the G30 lining is small. The $\Delta x$ of the GM-3 lining is also first decreased as the pressure increases, and the fluctuation is minimized at 2.5 MPa. Comparing Figs. 10(a)-10(c), the $\Delta x$ of the K25 lining is the largest showing the internal stretch of the K25 lining is the largest.
3.3 Dynamic observation of vibration in the $Y$-direction under different pressure conditions

The displacement in the $Y$-direction is the vibration amplitude. Figure 11 shows the amplitude of the friction lining in the $Y$-direction during the friction process under different pressure conditions. In Fig. 11(a), the amplitude of the K25 lining in the $Y$-direction increased first and then increased with the increase in pressure, and the smallest amplitude is at $2.5 \mathrm{MPa}$. The amplitude of the G30 lining also first decreased and then increased with the increase in pressure. The frictional vibration is minimized at $2.5 \mathrm{MPa}$ in Fig. 11(b). The frictional vibration of the GM-3 lining at $2 \mathrm{MPa}$ is the smallest in Fig. 11(c). Comparing Figs. 11(a)-11(c), the frictional vibration of the K25 lining is the lowest showing the friction stability of the K25 lining is the best. 

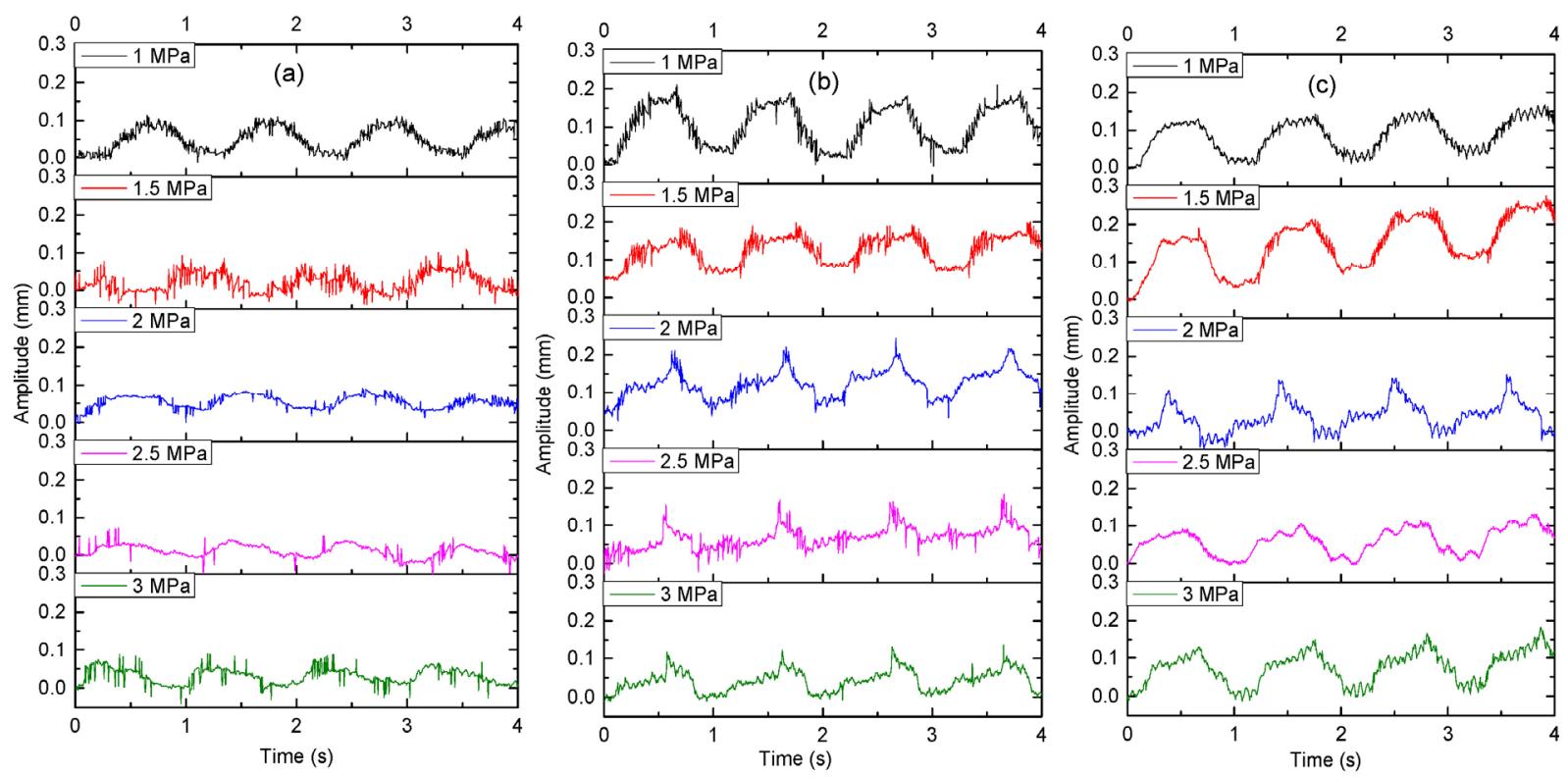

Fig. 11 Amplitude of the friction lining in the $Y$-direction: (a) K25 lining, (b) G30 lining, and (c) GM-3 lining.

\subsection{Frictional behaviors of the friction lining}

The friction force and COF are an intuitive reflection of the adhesion hysteresis friction. Figure 12 shows the friction force and the average COF of the friction lining under different pressure conditions. In Figs. 12(a)-12(c), when the friction started, it was in the adhesive stage, and the friction force increased
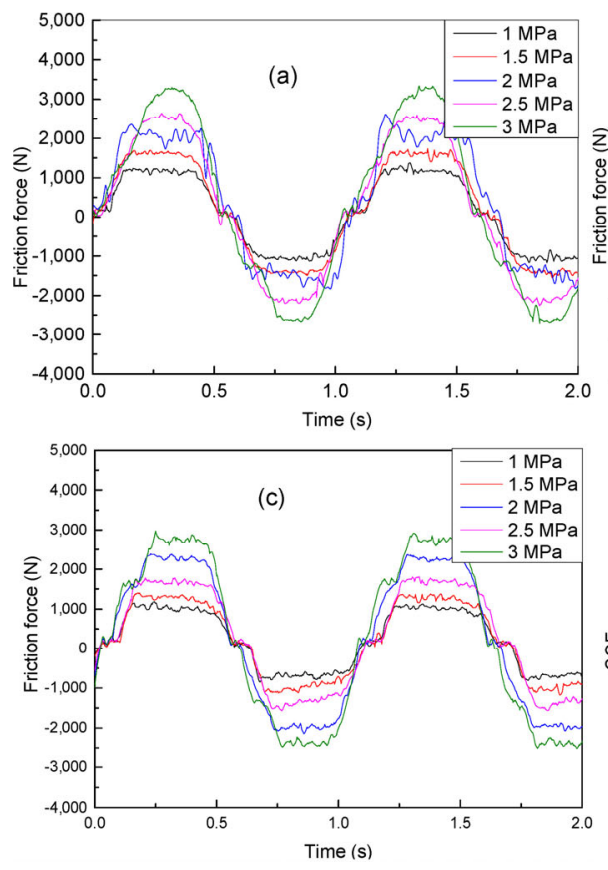

continuously. After increasing to the maximum value, there was a small decrease, and then it remained unchanged, indicating that it entered the sliding stage. After the end of the sliding, the friction force reduced rapidly and entered in the adhesive stage. Subsequently, it was a reverse change, which was still adhesion-sliding-adhesion. The friction of the K25 lining is the highest and that of the GM-3 lining is the
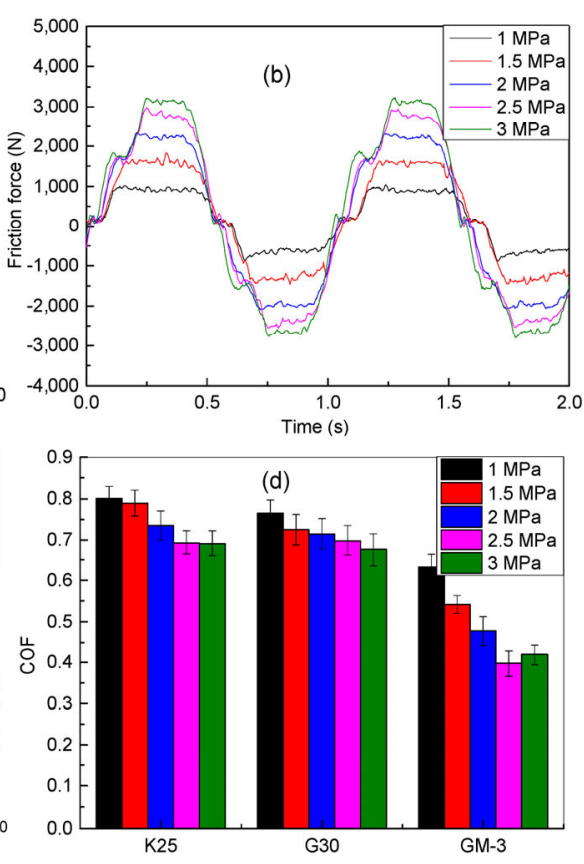

Fig. 12 Friction force and average COF of the friction lining under different pressures: (a) K25 lining, (b) G30 lining, (c) GM-3 lining, and (d) average COF. 
smallest. In view of the average COF in Fig. 12(d), the COF of the K25 lining is also the largest and that of the GM-3 lining is the smallest. Moreover, the $\mathrm{COF}$ decreases as the pressure increases. However, at $3 \mathrm{MPa}$, the COF increases. This is because the adhesion time of the GM-3 lining becomes shorter and the adhesion friction decreases, but the hysteresis friction increases, and the friction vibration amplitude is large. According to Moore's adhesion friction theory $[26,27]$, the COF is equal to the sum of adhesion $\mathrm{COF}$ and the hysteresis COF. When the increase in the hysteresis $\mathrm{COF}$ is larger than the decrease in the adhesion $\mathrm{COF}$, the COF will increase. Therefore, the $\mathrm{COF}$ increases at $3 \mathrm{MPa}$.

\section{Discussion}

According to Moore's adhesion friction theory, the friction of viscoelastic materials mainly comes from adhesive friction and hysteresis friction [27, 28], and the COF $(\mu)$ can be expressed by Eq. (1):

$$
\mu=\mu_{\mathrm{a}}+\mu_{\mathrm{h}}
$$

where $\mu_{\mathrm{a}}$ is the adhesive COF and $\mu_{\mathrm{h}}$ is the hysteresis COF.

$\mu_{\text {a can }}$ be expressed by Eq. (2):

$$
\mu_{\mathrm{a}}=K_{\mathrm{a}} \frac{1}{p^{0.2}} E^{\prime \prime}
$$

where $K_{a}$ is a constant (related to the properties of the material), $p$ is the contact positive pressure, and $E^{\prime \prime}$ is the loss modulus.

$\mu_{\mathrm{h}}$ can be expressed by Eq. (3):

$$
\mu_{\mathrm{h}}=K_{\mathrm{h}} \frac{E^{\prime \prime}}{\left(E^{\prime}\right)^{2}} p
$$

where $K_{\mathrm{h}}$ is a constant, $p$ is a contact positive pressure, and $E^{\prime}$ is a storage modulus.

Adhesive friction occurs on the frictional contact surface and the subsurface, as shown in Fig. 13(a). The contact and adhesion points of the micro-protrusions are continuously formed and destroyed. The adhesion area is enlarged, and the adhesion friction mechanism is mainly divided into three stages. In the first stage, adhesion occurred at the contact peak, and as the relative motion progressed, the internal molecular chain was stretched and deformed. In the second stage, the adhesion point was broken after the stretching reaches a certain value. The molecular chain relaxed and released energy. In the third stage, new adhesions were formed at a new location. Due to the repeated mode of the adhesion-stretch-fracture-adhesion, the energy is lost and released in the form of heat,

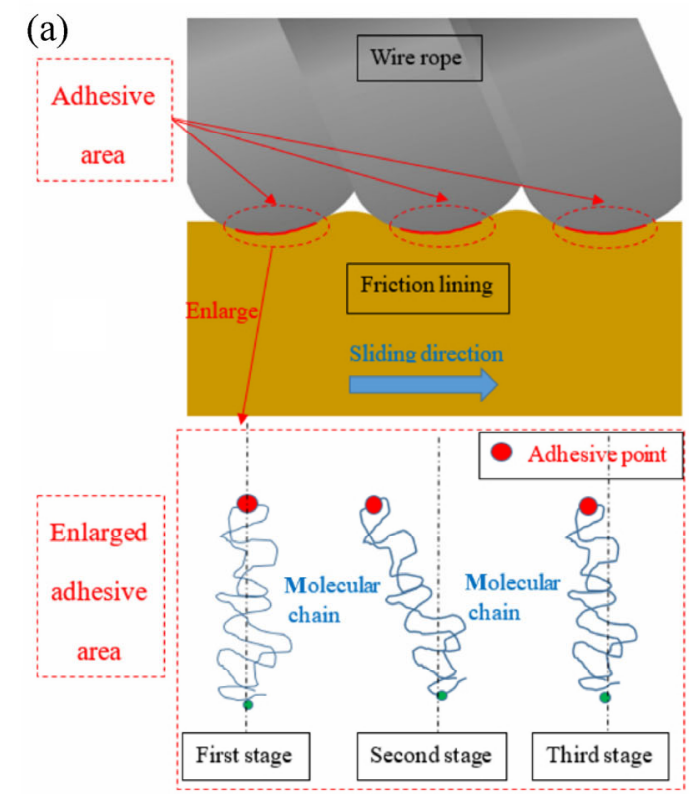

(b)

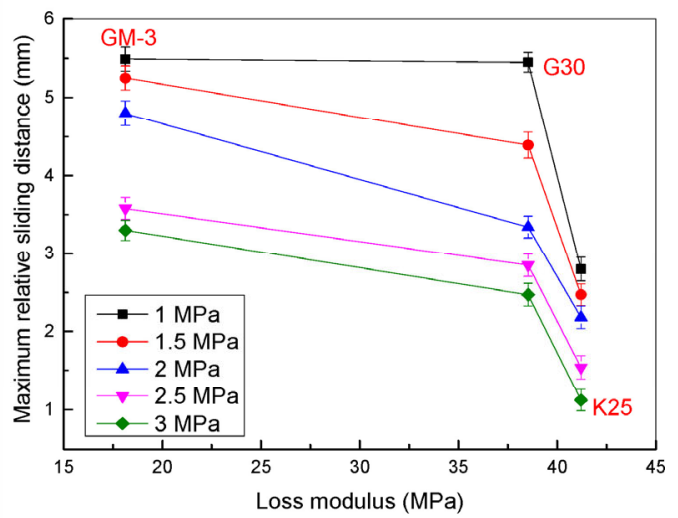

Fig. 13 Adhesion friction mechanism: (a) Diagram of adhesive friction and (b) the relationship between loss modulus and maximum relative sliding distance. 
producing frictional heat [29]. Figure 13(b) shows the relationship between the loss modulus and the maximum relative sliding distance of the friction lining. In Fig. 13(b), the adhesion friction is proportional to the loss modulus. The loss modulus of the K25 lining is large $[16,17]$. Thus, the adhesion friction is large, and the maximum relative sliding distance is small. According to Refs. [30,31], the COF is inversely proportional to the elasticity of the material and proportional to the viscosity. The relative pressure increases for stronger adhesion [32]. The adhesion friction is proportional to the loss modulus. The loss modulus of the G30 lining is smaller than that of the K25 lining. Therefore, the adhesion friction of G30 is smaller than that of K25. The loss modulus of the GM-3 lining is the smallest. Hence, the adhesion friction of GM-3 lining is the smallest and the maximum relative sliding distance is the largest.

Figure 14 presents a schematic of the hysteresis friction mechanism. Hysteresis friction is a repetitive periodic deformation of a viscoelastic material due to compression and sliding, resulting in a lag in the horizontal component (hysteresis friction) that hinders sliding and causes energy consumption during relative sliding. In this study, the hysteresis friction is well quantified by the $\Delta x$ in the sliding direction of the marked points 1 and 2 . The hysteresis friction is proportional to the loss modulus and inversely proportional to the storage modulus $[30,31]$. The larger the storage modulus is, the greater the elasticity of the material, and thus, the elastic deformation is smaller under the same load conditions and the hysteresis friction is smaller. The larger the loss modulus is, the greater the viscosity of the material, and the greater the friction inside the material, and thus, the hysteresis friction is greater. Figure 15 shows the relationship between hysteresis friction and the ratio of the loss modulus to the square of the storage modulus $\left(E^{\prime \prime} /\left(E^{\prime 2}\right)\right)$. It can be observed that the K25 lining has the largest value of $E^{\prime \prime} /\left(E^{\prime 2}\right)$; hence, the hysteresis friction is the largest. The GM-3 lining has the smallest value of $E^{\prime \prime} /\left(E^{\prime 2}\right)$, and thus, the hysteresis friction is the smallest. The hysteresis friction is proportional to the ratio of the loss modulus to the square of the storage modulus $\left(E^{\prime \prime} /\left(E^{\prime 2}\right)\right)$.

Figure 16 shows the relationship between the adhesion time, hysteresis friction, and frictional vibration amplitude of the friction lining with pressure increasing. It shows that as the pressure increases, the adhesion time increases, and the adhesion friction increases; the hysteresis friction first decreases and then increases. From the results of the friction and average COF with the increase in pressure, it is known that the hysteresis friction is dominant at low pressures, and the adhesion friction is dominant at high pressures. According to Ref. [29], the adhesion hysteresis friction of the polymer-polymer is dependent on the dynamic rearrangement of the outermost layer of the polymer at the shear interface. When the pressure increases, the contact area increases, the adhesion point increases, the adhesive contact area becomes larger, and the adhesion friction increases. When the pressure is smaller, the elastic deformation decreases as the pressure increases, the plastic deformation increases, the dynamic rearrangement of the material decreases, and the hysteresis friction decreases. After the pressure reaches a certain value, the internal molecular chain of the material is entangled, the damping is increased, and the hysteresis friction is aggravated.
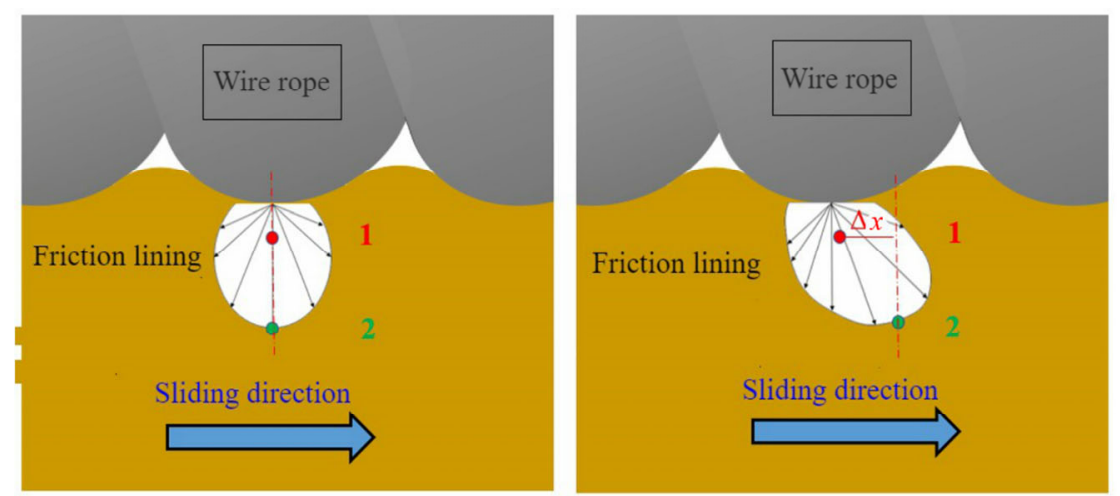

Fig. 14 Schematics of the hysteresis friction mechanism. 


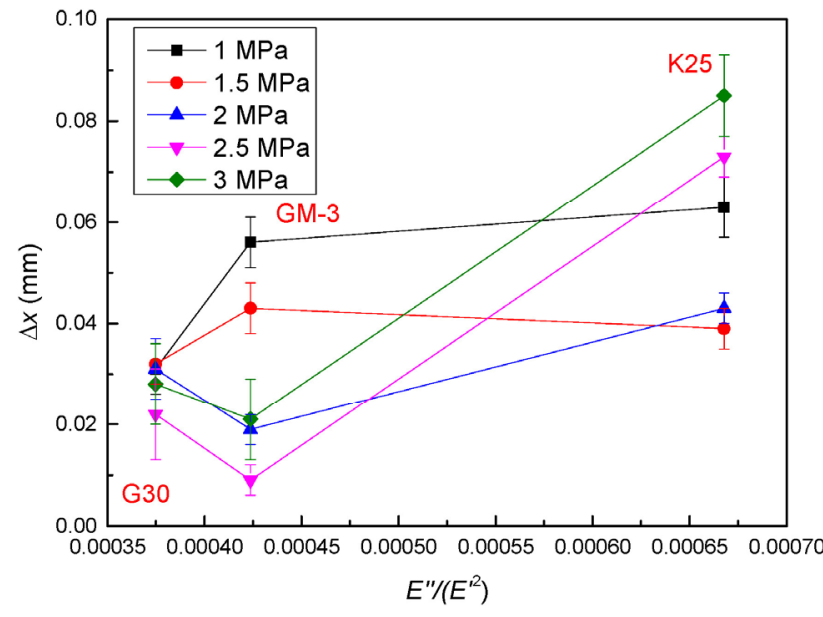

Fig. 15 Relationship between hysteresis friction and the ratio of the loss modulus to the square of the storage modulus $\left(E^{\prime \prime} /\left(E^{\prime 2}\right)\right)$.

The amplitude of the frictional vibration reflects the instability of the frictional interface, i.e., the severity of the damage. It can be observed in Fig. 16 that as the pressure increases, the amplitude of the frictional vibration decreases first and then increases, and the amplitude of the frictional vibration is the smallest at $2.5 \mathrm{MPa}$. The vibration amplitude of the K25 lining is the smallest. At low pressures, as the pressure increases, the adhesive time increases, whereas the hysteresis friction and frictional vibration amplitude decrease. Mainly because of the increase in pressure, the adhesive contact area becomes larger, and the adhesion friction is intensified. At the same time, the hysteresis deformation reduced and the friction surface is relatively stable. Therefore, the vibration reduced. However, when the pressure is sufficiently large, the hysteresis friction is intensified. This leads to an increase in friction and an unstable friction surface. Therefore, the vibration is slightly increased.

\section{Conclusions}

1) Through dynamic monitoring, the displacement changes of the friction lining and wire rope in the friction process under different pressure conditions were analyzed, and the adhesion and sliding stages were distinguished. The adhesion friction was analyzed by the relative sliding distance and the adhesive time. It was found that the adhesion friction is proportional to the loss modulus. The hysteresis friction is quantified by dynamically monitoring the difference in displacement of the friction lining in the sliding direction during the friction process. The hysteresis friction
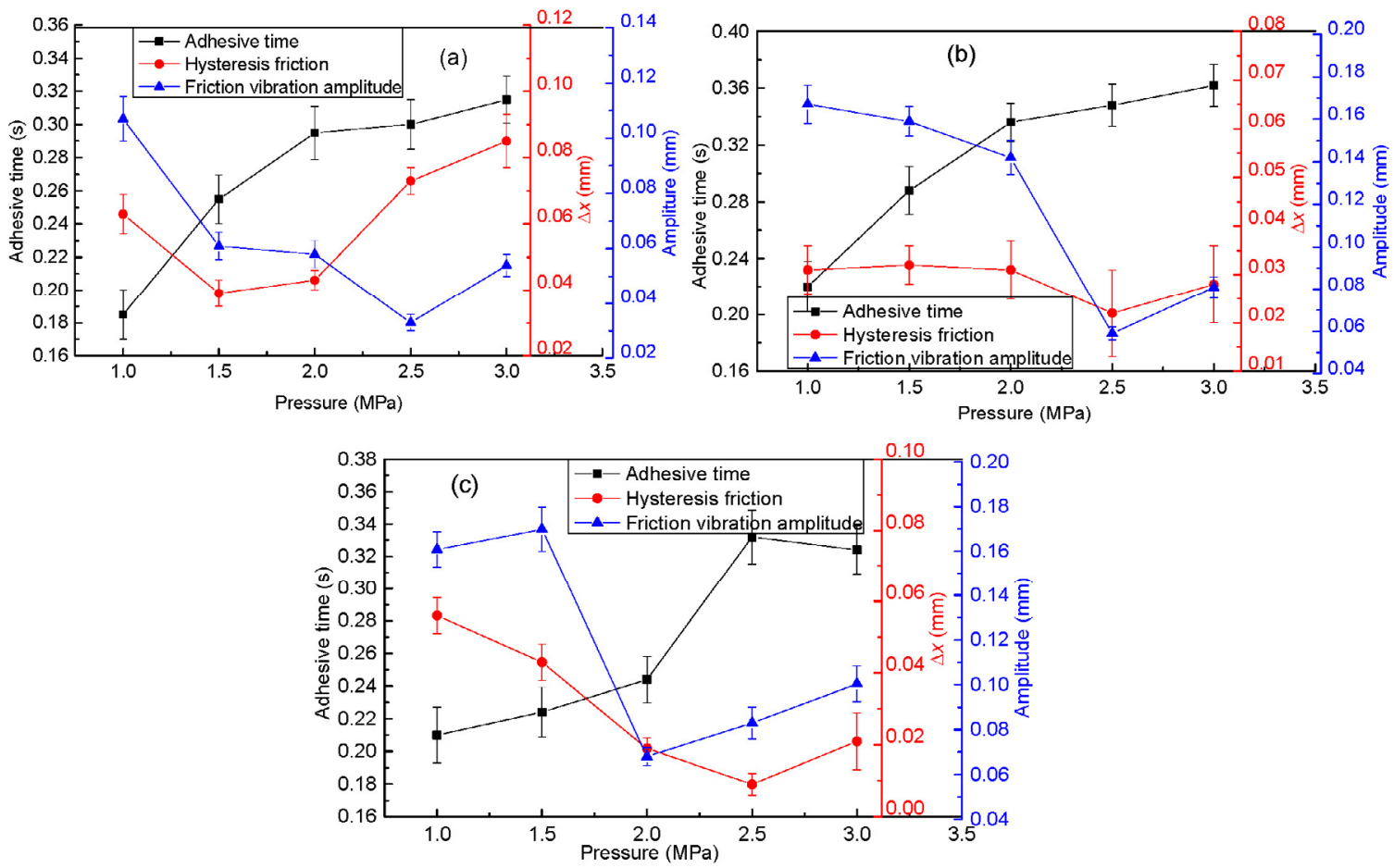

Fig. 16 Relationship between frictional vibration amplitude, adhesive time, and hysteresis friction: (a) K25 lining, (b) G30 lining, and (c) GM-3 lining. 
is proportional to the ratio of the loss modulus to the square of the storage modulus $\left(E^{\prime \prime} /\left(E^{\prime 2}\right)\right)$, and the hysteresis friction of the K25 lining is the largest.

2) The adhesion friction increases as the pressure increases. The hysteresis friction decreases first and then increases with the increase in pressure. The friction force and the average COF decrease as the pressure increases. This shows that hysteresis friction dominates at low pressures and adhesion friction dominates at high pressurses.

3) With the increase in pressure, the frictional vibration amplitude first decreases and then increases, and the frictional vibration is the smallest at $2.5 \mathrm{MPa}$. The vibration amplitude of the K25 lining is the smallest. At low pressures, as the pressure increases, the adhesive time increases, whereas the hysteresis friction and frictional vibration amplitude decrease. Mainly because of the increase in pressure, the adhesive contact area becomes larger, and the adhesion friction is intensified. At the same time, the hysteresis deformation reduced, and the friction surface is relatively stable. Therefore, the vibration reduced. However, when the pressure is sufficiently large, the hysteresis friction is intensified. This leads to an increase in friction and an unstable friction surface.

In this study, the adhesion hysteresis friction between interfaces was intuitively and quantitatively analyzed. The influence of different pressures on adhesion hysteresis friction and frictional vibration was analyzed. The result provides a simple and intuitive method for the research on friction transmission and vibration of viscoelastic materials, and provides a theoretical basis for determining the friction drive reliability of friction hoists.

\section{Acknowledgements}

This study is supported by the joint Ph.D. program of "double first rate" construction disciplines of China University of Mining and Technology (CUMT).

Open Access This article is licensed under a Creative Commons Attribution 4.0 International License, which permits use, sharing, adaptation, distribution and reproduction in any medium or format, as long as you give appropriate credit to the original author(s) and the source, provide a link to the Creative Commons licence, and indicate if changes were made.

The images or other third party material in this article are included in the article's Creative Commons licence, unless indicated otherwise in a credit line to the material. If material is not included in the article's Creative Commons licence and your intended use is not permitted by statutory regulation or exceeds the permitted use, you will need to obtain permission directly from the copyright holder.

To view a copy of this licence, visit http://creativecommons.org/licenses/by/4.0/.

\section{References}

[1] Ge S R. The friction coefficients between the steel rope and polymer lining in frictional hoisting. Wear 152(1): 21-29 (1992)

[2] Wu Y Q, Chen M M, Wang K, Fu G. A dynamic information platform for underground coal mine safety based on internet of things. Saf Sci 113: 9-18 (2019)

[3] Guo Y B, Zhang D K, Chen K, Feng C A, Ge S R. Longitudinal dynamic characteristics of steel wire rope in a friction hoisting system and its coupling effect with friction transmission. Tribol Int 119: 731-743 (2018)

[4] Feng C A, Zhang D K, Chen K, Guo Y B. Study on viscoelastic friction and wear between friction linings and wire rope. Int J Mech Sci 142-143: 140-152 (2018)

[5] Yao J N, Xiao X M, Peng A H, Jiang Y Q, Ma C. Assessment of safety for axial fluctuations of head sheaves in mine hoist based on coupled dynamic model. Eng Fail Anal 51: 98-107 (2015)

[6] Lü R G, Li T S. Effect of load on tribological behavior of NBR. (in Chinese). Lubricat Eng 26(6): 29-30 (2001)

[7] Wang J Z, Gu S F, Song N X. Friction and adhesion between tire and road surface. (in Chinese). Tire Ind 22(2): 67-70 (2002)

[8] Tong R T, Liu G, Liu L, Yu C J. Multiscale analysis on micro/nano scale adhesive sliding contacts. (in Chinese). Chin J Comput Mech 28(3): 400-405 (2011)

[9] Jrad H, Dion J L, Renaud F, Tawfiq I, Haddar M. Experimental characterization, modeling and parametric identification of the non linear dynamic behavior of viscoelastic components. Eur J Mech A Solids 42: 176-187 (2013)

[10] Jrad H, Renaud F, Dion J L, Tawfiq I, Haddar M. Experimental characterization, modeling and parametric identification of the hysteretic friction behavior of viscoelastic joints. Int $J$ Appl Mech 5(2): 1350018 (2013) 
[11] Jrad H, Dion J L, Renaud F, Tawfiq I, Haddar M. Experimental and numerical investigation of energy dissipation in elastomeric rotational joint under harmonic loading. Mech Time-Depend Mater 21(2): 177-198 (2017)

[12] Tambe N S, Bhushan B. Scale dependence of micro/nanofriction and adhesion of MEMS/NEMS materials, coatings and lubricants. Nanotechnology 15(11): 1561-1570 (2004)

[13] Bhushan B, Burton Z. Adhesion and friction properties of polymers in microfluidic devices. Nanotechnology 16(4): 467-478 (2005)

[14] Lafaye S, Gauthier C, Schirrer R. Analysis of the apparent friction of polymeric surfaces. J Mater Sci 41(19): 6441-6452 (2006)

[15] Sawyer W G, Wahl K J. Accessing inaccessible interfaces: in situ approaches to materials tribology. MRS Bull 33(12): 1145-1150 (2008)

[16] Chen K, Zhang D K, Zhang X J. Effects of viscoelastic properties of friction lining materials on their friction coefficients. J Tribol 139(3): 034502 (2017)

[17] Feng C A, Zhang D K, Chen K, Guo Y B, Hao T Q. Research on in-situ microscopic observation of dynamic contact and reciprocating sliding friction of GM-3 lining interface. Tribol Int 115: 179-190 (2017)

[18] Chromik R R, Strauss H W, Scharf T W. Materials phenomena revealed by in situ tribometry. JOM 64(1): 35-43 (2012)

[19] Krick B A, Vail J R, Persson B N J, Sawyer W G. Optical in situ micro tribometer for analysis of real contact area for contact mechanics, adhesion, and sliding experiments. Tribol Lett 45(1): 185-194 (2012)

[20] Czichos H. Tribology and its many facets: from macroscopic to microscopic and nano-scale phenomena. Meccanica 36(6): 605-615 (2001)

[21] Korres S, Feser T, Dienwiebel M. In situ observation of wear particle formation on lubricated sliding surfaces. Acta Mater 60(1): 420-429 (2012)

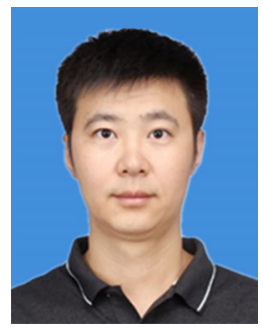

Cun-ao FENG. He is a Ph.D. candidate at China University of Mining and Technology. He was a joint Ph.D. student at the University of British Columbia (UBC) from
[22] de Beer S, KENMOÉ G D, MÜSER M H. On the friction and adhesion hysteresis between polymer brushes attached to curved surfaces: Rate and solvation effects. Friction, 3(2): 148-160 (2015)

[23] Gao L H, Wan C, Zhao J W, Yang Y, Chai Y D. Test and diagnosis for self-excitation of mine hoist. (in Chinese). Min Process Equip 35(8): 95-97 (2007)

[24] Wang D G, Li X W, Wang X R, Shi G Y, Mao X B, Wang D A. Effects of hoisting parameters on dynamic contact characteristics between the rope and friction lining in a deep coal mine. Tribol Int 96: 31-42 (2016)

[25] Kaczmarczyk S, Ostachowicz W. Transient vibration phenomena in deep mine hoisting cables. Part 1: Mathematical model. J Sound Vibrat 262(2): 219-244 (2003)

[26] Yao J N, Xiao X M. Effect of hoisting load on transverse vibrations of hoisting catenaries in floor type multirope friction mine hoists. Shock Vibrat 2016: 8598749 (2016)

[27] Moore D F, Geyer W. A review of adhesion theories for elastomers. Wear 22(2): 113-141 (1972)

[28] Moore D F. Friction and wear in rubbers and tyres. Wear 61(2): 273-282 (1980)

[29] Maeda N, Chen N H, Tirrell M, Israelachvili J N. Adhesion and friction mechanisms of polymer-on-polymer surfaces. Science 297(5580): 379-382 (2002)

[30] Li Q, Popov M, Dimaki A, Filippov A E, Kürschner S, Popov V L. Friction between a viscoelastic body and a rigid surface with random self-affine roughness. Phys Rev Lett 111(3): 034301 (2013)

[31] Zhao W F, Li Y, Lu Z P, Zhang T, Lu Z. The friction and wear behavior of polyethersulfone composites reinforced with carbon fiber. Tribology 20(6): 421-426 (2000)

[32] MALEKAN A, ROUHANI S. Model of contact friction based on extreme value statistics. Friction 7(4): 327-339 (2019)

2018 to 2019. He has published 9 journal papers. His current research interests cover tribology of soft materials, friction reliability of mining machinery, viscoelastic materials, and wear-resistant materials. 


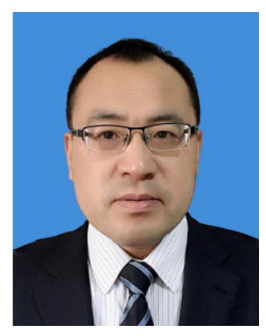

De-kun ZHANG. He received his Ph.D. degree from China University of Mining and Technology in 2003. He is a professor at China University of Mining and Technology since 2008. His current research interests cover fretting, friction reliability of mining machinery, bio-tribology of artificial joints, bionic design of functional materials, and wear-resistant

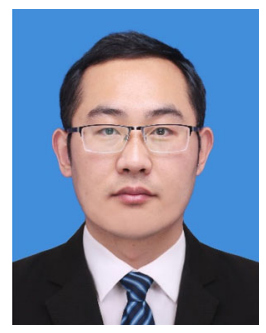

Kai CHEN. He received his Ph.D. degree from China University of Mining and Technology in 2015. He is currently an associate professor at China University of Mining and materials, etc. He has published 2 monographs, more than 180 papers, of which over 100 publications are included in SCI, and he has also obtained more than 30 patents for invention. His main academic part-time jobs include the deputy chairman of the Tribological Branch of the Chinese Mechanical Engineering Society, the chairman of the Tribological Branch of the Jiangsu Mechanical Engineering Society, and so on.

Technology. He has published over 50 journal papers. His current research interests cover the bionic design of functional materials, tribology of soft materials, and bio-tribology of artificial joints. 